\title{
Los indios y la Constitución de 1812
}

Christine Hünefeldt

ES POCO LO que se conoce de los resultados y consecuencias de la implementación de la Constitución española de 1812 en el Perú. Hasta ahora sólo ha sido analizado este período a través del lente de los delegados y las propuestas bastante retóricas presentadas en Cádiz; a lo más, secundariamente cuando se han descrito los levantamientos del Cusco y Huánuco o sólo al interior de la documentación que revisa todo el período pre-emancipación ${ }^{1}$.

Las Cortes funcionaron en España de de e! 24 de setiembre de 1810 hasta el 10 de mayo de 1814, período dividido en tres momentos: primero, las Cortes generales y extraordinarias que duraron hasta setiembre de 1813. Luego la primera legislatura extraordinaria, que se instala el 25 de setiembr: de 1813 y dura hasta el 12 de febrero de 1814 , y finalmente la segunda legislatura extraordinaria que va desde el 10 de marzo de 1814 hasta su clausura forzada el 10 mayo del mismo año ${ }^{2}$. Entre estas etapas la más importante fue la primera. Se discutieron en estos años los supuestos básicos de la nueva Constitución, los problemas en torno a la representación política de las colonias y se avanzaron los planteamientos en torno a las relaciones económicas entre metrópoli y colonias. En ningúni mimrato, sin embargo, estuvieron presentes todos los delegados de las colonias.

(*) El presente trabajo es parte de una investigación más amplia que ha sido posible realizar gracias al apoyo brindaco por la Fundación Ford. 
En primer lugar, porque encontraron serias dificultades para realizar el viaje, dificultades que fueron expresadas sobre todo por la falta de recursos para su envío ${ }^{3}$;en segundo lugar, porque las enormes distancias entre metrópoli y colonia (el viaje en aquel entonces duraba entre tres y cuatro meses), hacían que los diputados de las colonias siempre llegaran demasiado tarde. 'I'odavía en 1815, cuando ya estaban clausuradas las Cortes, habían delegados que en Lima estaban esperando que el virrey les ctorgara sus viáticos para emprender el viaje a Cádiz.

Si bien era cierto que las arcas fiscales estaban exhaustas por los continuos gastos reyucridos hacía tiempo en el mantenimiento de las tropas para impedir la incursión de las fuerzas patriotas altoperuanas, o para sufocar los diferentes levantamientos que se produjeron a partir de 1809, el problema de fondo eran las relaciones y contradicciones que la instalación de las Cortes habían suscitado en las colonias, la formación de bandos liberales $\mathrm{y}$ conservadores que pugnaban por el poder, acompañado todo ello por protestas y alzamientos de los indios.

Los alcances y consecuencias fueron vastos. Todo el ideario liberal que hilvanaba los diferentes capítulos de la nueva Constitución no podía obviamente afectar y significar para todos los sectores sociales lo mismo. Con mucha mayor razón cuando se tratara de reunir aspiraciones, deseos, intereses y contradicciones de una sociedad, no sólo colonial, sino además fraccionada por grupos de interesess económicos y étnicos. El reordenamiento político anhelado a través de las Cortes implicaba un cambio en las relaciones de poder inherentes a la sociedad colonial. Atacaba privilegios de grupos consolidados y abría al mismo tiempo caminos de reivindicación a grupos oprimidos, que en el caso peruano, no eran sólo los pobres, sino también los indios y los negros. Se trataba de reivindicaciones elementales pero trascendentes. ¿Serían el indio y el negro considerados ciudadanos con igualdad de derechos y deberes? Sin duda el delirio liberal de la época así lo exigía, pero los prejuicios existentes, y sobre todo, el sistema que funcionaba gracias a la existencia de éstos, lo negaba. Discurrir en torno a las declamaciones y los argumentos de los diputados a Cortes sería un esfuerzo duplicado, puesto que al respecto existe un trabajo de James F. King ${ }^{4}$ quien analiza las suspicacias y falacias de su contenido. Lo que me interesa describir y analizar en las páginas siguientes es la contraparte, es decir, cómo se tradujo en las actitudes de los diferentes sectores 
sociales en la colonia, económica y étnicamente antagónicos, este intento liberal. Ello incluye tanto las respuestas de tipo formal a las novedades de las Cortes (abolición de la mita, el tributo y los repartos), como las movilizaciones armadas durante este período, de las que las principales fueron la de Huánuco de 1812 y la del Cusco de 1814, dejando de lado por ahora la movilización de los negros, que no sólo excedería el espacio fijado sino también los límites del tema propuesto.

Las reacciones en su conjunto tuvieron muy poco en común con la imagen presentada y divulgada por los diputados a Cortes.

\section{0-LA CUESTION INDIGENA}

Aproximadamente el $60 \%$ de la población colonial estuvo formada por indígenas. Su simple presencia numérica los convertía en uno de los puntos y problemas centrales. No faltaron en las Cortes argumentos en torno a la "tradicional pereza", que apuntaban hacia el mantenimiento de los tributos, mitas y repartos. Pero otros levantaron su voz en contra, ya sea defendiendo el espíritu liberal de la época y la Constitución, cuando decían que: "esta creencia vulgar en el siglo 16, a los pocos días del descubrimiento de América, no debe propalarse en el siglo 19, donde merece un desprecio universal" 5 , o cuando algunos de manera mucho más pragmática y feliz afirmaban que los indios "no trabajan porque cuánto más ganan, más les roban: hacen bien" 6.

Por razones de propio interés, los criollos en Cádiz no podían dejar de lado el problema del indio. Necesitaban que el indio fuera considerado ciudadano de la monarquía española, porque gracias a ello aumentaban los asientos de los representantes coloniales. Pero, al mismo tiempo, no podían dejar que los indígenas tuvieran una representación real en las Cortes, porque hubieran corrido el riesgo de que los indios ocuparan más asientos que los criollos. Así se pactó un término medio: el indio podría elegir, pero no ser elegido ${ }^{7}$. La discriminación y los privilegios se mantuvieron a través de una legislación étnicamente selectiva. Después de todo, ¿se podía esperar en 1812 que españoles, aun los nacidos en territorio colonial, aceptaran la igualdad o se identificaran con los problemas y el mundo americaro habiéndolo marcado desde el inicio con un signo de inferio- 
ridad para justificar su dominación? Sus conflictos con el indio (y el negro) fueron vivo reflejo de esta incapacidad. Pero, por el otro lado, tendieron a olvidar que la sociedad indígena había sufrido modificaciones. ¿Qué pensarían de estas resoluciones y estas actitudes un Dionisio Inca Yupanqui, quien en voz alta se autotitulaba indio, un Pumacahua, presidente interino de la Audiencia del Cusco, también indio, un Manco Yupanqui, Protector General de Indios de Lima, buen conocedor del latín, versado en inglés y francés y considerado el mejor graduado en griego de la ciudad, José Huapayo, indio vice-rector del Colegio del Príncipe, pasante de San Carlos, o esa familia de "alta alcurnia" de Lima, que trazaba "su descendencia con inegable certeza desde los incas" 8? Son éstos, ejemplos aislados de la inserción indígena en la vida política colonial. Además existieron, como se verá, numerosos defensores y organizadores de las reivindicaciones comunales, que conocían muy bien las debilidades y posibilidades que les ofrecía el sistema colonial, y supieron aprovecharlas para conquistar beneficios en favor de la "nación india". Todo ello, fuera de comerciantes y agricultores que tenían intereses concretos que definir y pelear. En su conjunto tenían las aspiraciones indígenas una coherencia peligrosa, a la vez que mostraban en los hechos la imposibilidad de mantener $y$ redactar una Constitución cuyo contenido se trazaba a lo largo de líneas étnicas. Dadas estas condiciones, la apertura e incorporación más amplia de los sectores discriminados, llevó a consecuencias inesperadas. No es en vano que ya en 1812 , Valenzuela, escribano de la Real Hacienda de Puno, afirme que:

“...Se advertírá la decadencia de algunos ramos por la inercia de los indios nue con la libertad de tributos han dado de mano a toda especie de labores, sin que sean suficientes la fuerza de los mandones a contraerlos al trabajo por la altanería que se ha descubierto en este poco tiempo en ellos..." 9

\section{2:-EL TRIBUTO}

El tributo cumplía, durante este período, una función distorsionadora de la situación económica real de la colonia, y ello se tradujo muy claramente en las diferentes respuestas de sectores indígenas tanto a raíz de su abolición como a raíz del intento de reintroducirlo bajo otro nombre por parte del virrey Abascal.

Las reacciones variaron desde cartas de profundo agradeci- 
miento al Rey hasta la resistencia armada contra la reintroducción de la contribución provisional, única o voluntaria. Por primera vez en la historia colonial, en efecto, las distancias entre metrópoli y colonia parecían acortarse. Por encima de los usuales laberintos burocráticos y la intermediación falseadora de los grupos locales de poder, las comunidades y los pueblos más remotos tuvieron la posibilidad de comunicarse, por intermedio de sus voceros o directamente con el Rey de España mediante los Diputados a Cortes.

Fueron el cabildo de indios de Lambayeque y el cabildo cornún de Catacaos, las comunidades de Huamanco, Cascas, San Pedro, Pueblo Nuevo, Chiclayo, Trujillo, Arequipa, Sechura, Monsefú, Contumazá, Chacas, Ferreñafe, Andahuaylas, Casma, Pallasca, Chancay, Catacaos, Cajamarca, Huamanga, Ica, Tarapacá, Cámaná, 'Tacana, Ocros y Puno quienes suscribieron cartas dirigidas al Rey agradeciendo la abolición del tributo ${ }^{10}$. El contenido de estas cartas era el siguiente:

\begin{abstract}
"Señor, el paternal amor y desvelo con que nuestro incomparable Monarca el señor D. Fernando VII y en su real nombre el Consejo de Regencia, depositario de la soberanía, procura la felicidad de sus va. sallos, difundiendo sus graclas sobre todos los de este reyno, hace al cabi'do de naturales de esta capital de Lambayeque el objeto de sus piedades, ha exemplo de los Augustos Católicos Soberanos sus ascendientes, mirando desde esas distancias a sus miserables indios con aque. lla ternura paternal propia del pladoso corazón de V.M. derramando sus beneficios con preferencia a los demás vasallos. Estos conocimien. tos, Señor nuestro amo, llenan a este pobre cablldo y a su comunidad de complacencia; y que nuestra humlldad y graclas que damos por el bien $y$ exención de tributos con que nos ha distinguldo, lleguen a sus oícios, porque no hay bien que no nos desee, reconoclendo que era el único derecho que pagaba la nación en reconocimiento del vasallage debido a su soberanía y suprema protección, consultando nuestro alivio, y rue se haga menos molesta una contribución que por si misma era tan corta: por lo que cumiso y rendido da este miserable cabildo, justicia y regimiento por si y a nombre de su común las debidas gracias a! Consejo de Regencia, que hoy representa a nuestro Católico Monarca, a quien se va a dedicar una Misa Solemne en acción de gracias el dcmingo 20 del corriente con iluminación de calle; pidiéndole a Dios nuestro Señor dilate muchos años la real importantísima persona $\mathbf{y}$ el feliz reinado de V.M., para amparo de la nación, y demás fieles vasal!os..." 11
\end{abstract}

Si bien la participación indígena en las grandes decisiones políticas en España, y a nivel de los ayuntamientos fue escasa, en la enumeración del lugar de procedencia de estas cartas es fá- 
cilmente visible que la inovilización indigena en torno a este problema que tan directamente afectaba sus vidas y sus intereses fue masiva, desde Sechura a Tacna, desde Cajamarca a Puno.

Pero, ya en 1812, la abolición del tributo no significaba necesariamente una ventaja para algunos sectores indigenas. No lo era para aquellos que, en cambio, verian pensionados sus productos agrícolas al querer introducirlos en los centros urbanos. Al ser considerados como ciudadanos españoles sufririan nuevas pensiones, y por ser indios, a pesar de todo, nuevas extorsiones que gracias a estas disposiciones se hacian posibles. Es la misma situación que fue descrita años más tarde por una Comisión de I etrados reunida por el libertador para estudiar la situación del indigena. Decian en un infonne que "la tasa del tributo les defendia de selacjantes exlussiunes, pues era una contribución única. Abolido el tibuto, ha caido sobre los indios una nube de calamidades, de manera que, en cambio de una igualdad nominal, han perdido las garantias civiles a que debian la exención de mayores males (..). Desde que el indio pagaba su tasa -insistía - quedaba libre de otras molestias de parte del fisco, pudiendo introducir sin estorbo al mercado los efectos de su industria para reducirlos a dineru. Sus pobres cargas son ahora registradas y pensinnadas a las puertas de los lugares" 12 . Las leyes de Indias, en efeclo, decian "que los indios están exemptos de contribuir Alcabalas de las especies de su industria, crianza y labranza, cuando lo acrediten con las Guias de Aduanas ó con las certificaciones de los Curas Parrocos que las expiden, si la extracción procede de lugar donde no estén establecidos como también en el que las conducen de su cuenta sin haber trasferido Dominio. Si faltan acjuellas circunstancias se les cobra la Alcabala por los efectos que se recelase puedan pertenecer a Individuos obligados a satisfacerla, y que se valen de ellos para defraudarlas" 13. No es sorprendente, que en zonas como éstas los indios ofrecieran seguir contribuyendo "voluntariamente" con el tributo, y que los criollos se convirtieran en ardorosos defensores de la abolición del tributo. Aun aceptando que la continuación voluntaria del tributo pudiera ser resultado de una sumisión al Rey, debidamente propagandizada por años y siglos por los grupos locales de poder, o acaso resultado de las nuevas extorsiones que sufrian por el cobro de alcabalas e impuestos, no deja de ser sorprendente que en zonas como Caylluma (Arequipa) Cusco y La Paz ${ }^{14}$ ya en 1805 los propietarios criollos y españoles en un in- 
forme al Consulado de Comerciantes de Lima se quejaran de las recargadas pensiones que sufrian y aseguraran, luego de una larga enumeración de cuales eran, de que "sólo los indios no descuentan este cargo y la conducción de granos la hacen en sus cabalgaduras puede asegurarse en ellos la utilidad de la agricultura sobre los españoles" ${ }^{15}$. Y fue en estas zonas, donde surgieron pedidos y ofrecimientos para continuar con el pago de los tributos. Es así como se entiende, o se puede entender, la actitud de un Pumacahua en 1781 y en 1812. En 1781 Pumacahua había pedido que se exonerara a los indios de Chincheros del pago de tributos apoyando su argumento en su lealtad y constancia durante el combate "contra las fuerzas tupamaristas. En esa ocasión su pedido le es negado por los atrasos (en) que está la Real Hacienda" 16. En diciembre de 1812 Pumacahua, en nombre de los indios de Chincheros hace entrega de 800 pesos "en clase de donativo voluntario comprometiéndose juntamente a dar dos pesos anualmente cada uno de ellos mientras durase la presente guerra". 17

Sin embargo, la actitud de Pumacahua no refleja la totalidad de los sentimientos indígenas en relación al pago de los tributos. Mayor fue la resistencia y visiblemente la división al interior de las comunidades y los pueblos indígenas.

Comenzaron a surgir voces más fuertes al interior de las mismas comunidades contra sus caciques, contra la apropiación de éstos de los recursos vitales de la comunidad. Cuando Eugenio Quispe y Pedro Itiylari, indios tributarios de la comunidad del pueblo de Tiquillaca, Intendencia de Puno, promueven un pleito contra la Cacica Margarita Tinajeros, acusándola de no pagar jornales por los trabajos que efectúan en sus campos, de apropiarse de los recursos provenientes de la extracción de la sal, de la venta de aguardiente, negándose además, por los maltratos que reciben, a considerarla cacica de dicha comunidad ${ }^{18}$, demuestran no sólo la existencia de conflictos al interior de la sociedad indígena, sino también el conocimiento de los mecanismos para librarse de las extorsiones de sus opresores inmediatos y cercanos. Un hecho similar ocurrió en el partido de Cajatambo donde "tres individuos de nuestra parcialidad" dicen los indios de la comunidad de Racayán, habian alquilado pastos comunales a los hacendados vecinos, hecho que iba en contra de las intenciones y los derechos de la comunidad entera ${ }^{19}$. 
Rompían con su acusación posibles conciliábulos entre las fracciones de la sociedad dominante criollo-española, con los principales y líderes indígenas que habían dejado de representar los intereses de las comunidades. Estas voces se alzaban cada vez con mayor frecuencia, y no eran solamente resultado de la pérdida del ascendiente ideológico del cacique entre los indios, sino también de su poder económico, resultado de una creciente diferenciación interna de las comunidades ${ }^{20}$. Esta situación se vio acrecentada por los intentos de abolición del tributo. Cuando A. Bornas, cura del partido de Azángaro afirmaba "que la contribución ramo principal del Herario, la sobrelleva en mucha parte, y con mucha pujanza los Segundos, Hilacatas y Alcaldes de Campo con ruina cierta de sus cortísimos fondos, quedando los de esta clase, que son de los Principales, de dose a dies y seis resentidos en cada un año, y en cada Pueblo" y que, por ejemplo, en el pueblo de Ayaviri "solos los Alcaldes y algunos Principales contestaron, que contribuían con la donación de lo que buenamente pudiesen... es igual la resistencia de todos estos Pueblos" ${ }^{21}$, señalaba muy claramente la no uniformidad de las intenciones y reacciones al interior de la sociedad indígena, al interior de las comunidades. A partir de esta diversidad de actitudes no es sorprendente encontrar en este período, y más tarde en las luchas por la independencia, una masiva presencia indígena tanto en las filas patriotas como realistas.

\section{3?-LAS RELACIONES SERVILES}

Una faceta distinta del mismo problema fue la exigencia creciente de pago de salarios por los trabajos realizados, que tendían no sólo a la paulatina abolición de la mita sino que rompían las relaciones de tipo servil que ésta implicaba. La escasez de mano de obra, sobre todo en los sectores agrícolas altamente rentables, fue el sustento lógico de estas exigencias. En la hacienda de San Antonio de Colpa, doctrina de Magdalena de Cajatambo. los mitayos abandonaron sus obligaciones de pastoraje y sembrío, mientras "casi los más pueblos se han resistido de dar los acostumbrados mitayos (...) principalmente los del la pachaca Huancas de la doctrina de Gorgor, y de este modo Sr. me veo en muchos aprietos", dice el mayordomo de la mencionada hacienda. En esta zona surgió un indio, José Naupari, 
que se hizo apoderado de los indios de esta zona (y otras) para luchar contra las imposiciones del hacendado. L,os cuatro alcaldes, bajo su amparo y tutela, en efecto, justifican la actitud de los mitayos aduciendo que:

"Ios suplicantes ni sus respectibas comunidades no son tan tontos que franqueándoles utilidad en el Pastoreaje quisieran separarse por. que nuestro carácter natural es que nos paguen y ver el dinero efectibo ... Quitada la mita en el todo. D. Juana (propietaria de la hacienda) tendrá Indios de sobra para que les custodie sus ganados por. que saven que le han de pagar. Que hoy con el nombre de Mitayos no les pagan y por eso la resistencia. Mas c'aro, queden libres de parte á parte, no havrá querellas, ni menos havrá maltratos. como la expe. riencia lo demuestra en las Estancias del Reyno. En las minas. En las Chacras y en los Obrajes, que no sólo van voluntarios, sino se forman un Pueb'o considerable de los Congregados ..." 22

La resistencia, así vista, aumentaba cuando los indios necesitaban su propia fuerza de trabajo, como en los centros productores de vid de la costa sur, porque ellos lambién cultivaban el mismo producto y estaban por tanto, sometidos a la misma presión estacional. En épocas de sembrío y cosecha subían los salarios, y los hacendados de la zona competían por la mano de obra, y muchas veces la única forma de reclutarla era recurriendo a las imposiciones serviles, por intermedio de los alcaldes o caciques. Estos:

"Por no tener tropiezos de disgusto con el (el juez subdelegado de Ica), le facilitaran 40 hombres, los que es natural haigan ido contra su voluntad: por quanto algunos de ellos se han rebuelto, por que el trato que se les da. es igual al de 'os Negros. asegurándose que comen de la Paila con ellos, se les hace madrugar a las horas que estos esclavos lo verifican para salir al travajo, sin guardar aquellas horas que le competen como a jornaleres voluriar:ss. che trman el trabajo por estajo y dan principlo a el. quando lo hallan pcr mas combeniente. El obligar a los Indios de Ica salir de su Reducción á distancia conciderable, qual es a la de Pisco. en este tiempo, es hacerle un notorio agravio ... Es una época en que esperan con ancia lleguen las aguas para regar sus tierras. porque sólo gozan de este beneficio en abenidas de aguas. y si este se pasa, mo pueden regar, quedando sus tierras inhaviles para sembrarlas. Fs la ocasión en que recogen sus cosechas de Uba:, hacen sus pisas, sacan el vino, para reducirlo en aguardiente por medio de la industria de las albercas, y alambiques, y como asi los Indios, como Españoles, y otras Castas andan entretenidos en estas operaciones, se hal'an los peones bien escasos, y para conseguirlos se le da mayor precio de lo estipulado para que con jreferencia á otros se dediquen al trabajo". 23 
Es dificil pensar yue los hacendados acataran el libre movimiento de la mano de obra, o el pago de salarios si tenían que contar con el hecho de que los indios preferirian trabajar sus propias chacras. Los conflictos que estas reivindicaciones provocarian se traslucen con suma nitidez. La resistencia rebasó los límites netamente agrarios. Cuando en Huaraz se quiere reclutar mano de obra de las comunidades adyacentes para concluir la construcción de una pila de agua, los indios no solamente exigen salarios sino que además manifiestan su desinterés, y consideran que la pila de agua debería de ser construida y pagada por aquellos que se beneficiarian con su instalación. 24

Estas muestras bastante claras de la voluntad indígena, que no permitian una exclusión en la participación del destino político de la colonia, encontraron una resonancia multiplicada, cuando fue canalizada por defensores de la causa indigena. Surgieron, en efecto, durante este periodo, indios que se autoproclamaban defensores de sus congéneres, y comenzaron sistemáticamente a promover juicios contra abusos, contra la mita, contra el pago de tributos, y por la recuperación de tierras usurpadas. Estaban subvencionados por las mismas comunidades, o algunas veces por algunos individuos dentro de la comunidad. Estos defensores expandieron paulatinamente su influencia sobre amplias comalcas, y pudieron en algunos casos cerrar viejos comfliclos entie las mismas comunidades, reorienlaludes su colesa hacia un entenigo distinto: el hacendado, el cura, incluso llevar a la destitución del Subdelegado. Tadeo Efio, quien actuó en Conchucos y Trujillo, y cobraba a cada indio un peso por la defensa que hacía en Lima y en los tribunales locales ${ }^{25}$, fue uno de los más exitosos. También lo fueron Bentura Calderón en Cajatambo, Nieves, Mullay, Pachangara, Curay y Rapaz ${ }^{26}$ y el ya citado Naupari. La fuerza de estos defensores, así como el relativo éxito de sus actuaciones estuvo ciertamente sustentada por el apoyo indígena, que ellos a su ve' fomentaron. Para lus criollos y españoles eran espectros que habían que combatir (así como lo sugieren los juicios iniciados por los grupos locales contra estos abogados indios), no sólo porque la intermediación de éstos significaba límites a las extorsiones y despojos, sino porque también se comenzó a cuestionar la legitimidad de sus actuales pertenencias. Se revisan títulos de propiedad, se advierten 
usurpaciones, y se hacen reclamos. Frente a ello, es sorprendente la actitud y la decisión del Fiscal Protector Gene!al, Irigoyen, a la vez que describe la interferencia de los grupos locales de poder, quien dice:

“...Lejos de acreditar el delito que se acusa a este indio (Eflo) solo persuaden el odio que se le tiene, y el empeño que hay para arruinarlo, porque favorece a los de su Nación, y quiere defenderlos de las estafas y opreciones que padecen ... (en una acusación hecha contra el por el milicano Fc. Xavier Noriega, dueño de la hacienda Collambay, Irigoyen considera que no es imparcial) ... porque sabe el pleito que con este individuo tienen los Indios de Sincicap, a quienes á quitado el agua, y era consiguiente su enemistad con Efio, por !a protección que también había hecho de dichos Indios (...) y ante V.A. corre otra causa que con igual injusticia sigue contra el mismo Efio, D. Pablo Madalangoitia, imputándole el incendio de su Hazienda, y también con. moción de sus Indios Sirvientes, sólo porque procuran defenderse de la opreción y tirania con que se les trata. Con Efio se ha hecho ahora lo que siempre se ha acostumbrado hacer con quantos Indios reclaman en los Tribunales sus agravios, y perjuicios; y es perseguirlos, apricionarlos, y figurar!es delitos, para que atemorisados y agoviados, desis. tan de sus justas pretensiones; dando lugar a la conmoción de los Pueblos, que es el crimen que se le imputa á Efio ..." 27

"No tenemos Pasiensia, ya basta" 28, afirmaban el común de Racayán y Piscamarca, ,y resumían con ello la cólera retenida de siglos, justa cólera, que en algunos parajes llevaría al alzamiento armado contra la reintroducción de las cargas coloniales: ahí donde este acto fue entendido como una renovada voluntad del gobierno de querer restringir la libertad, de acentuar el vasallaje que su pago implicaba. Los agricultores y tejedores de Jipijapa se violentaron a razón del decreto de Abascal, traducido al quechua, de que "los que combengan en continuar con la quota del que era Tributo, no se les ha de exijir vajo alguno pretexto el pago de derechos reales, nuebas obenciones ni otras gabelas; pues han de quedar en poseción de las mismas exenciones y privilegios que les conceden las leyes" 29. Ante arcas fiscales vacías por la ausencia de la contribución indígena, el carácter voluntario impreso en este decreto fue sumamente dudoso, y los hechos lo confirmaron. El gobernador de Jipijapa, Luis José de la Vega describia las razones del motín y la reacción de la siguiente manera:

"...con el objeto de prevenir a los Indios la obligación (!) que tienen desde el tiempo presente, á contribuir el pago de la Unica Contribución hice concurrir a los Indios de Jipijapa.. después de la Misa Mayor, haciendo igualmente asistir a los demas vecinos y comerciantes 
de el lugar para que como testigos presenciasen lo que resultase, y haviéndoles requerido con la lenidad necesaria, al principlo que se devia dar á esta Contribución respondieron quatro Indios haciendo formal Cabesa entre ellos diciendo Francisco Jalca que to que el Rey daba, no quitaba, y que no pagaba; Gonzalo Parral dixo: que no queria cautibarse siendo hombre libre: Mariano Pin expresó resolutivamente que no queria pagar por ningun motivo, por haverle dado el Rey la Livertad. y Jacinto Suares se opuso igualmente disiendo que no pagaba aunque le quitasen el pescueso, expresándose todos igualmen. te en a'tas voces, en términos que causaron exemplo á los demás; que por ellos hicieron igual resistencia al pago..." 30

Ante argumentos así, el virrey no tenia ninguna fuerza para compeler a los indios al pago, y en efecto, el juicio concluye en 1818, con la liberación de los indios y la cesación en el mando del gobernador. 31

De lo descrito hasta aquí se desprende el carácter de la movilización indígena en torno a las innovaciones proyectadas por las Cortes, al mismo tiempo es un presagio oscuro de lo que serían las consecuencias y los resultados de los dos grandes levantamientos que se produjeron durante este período. ¿Cuáles serían las actitudes de los grupos locales durante las contiendas? Sabían muy bien que sin la participación indígena, no sólo eran débiles sus aspiraciones a los asientos en la metrópoli, sino también el respaldo que sus reivindicaciones concretas podían tener. La ilusión independentista de algunos sectores que se discernía con cada vez mayor nitidez, no podía con mayor razón, excluir la presencia indígena. Pero ¿estarían dispuestos a admitir junto a sus clamores, las reivindicaciones indígenas, podrían controlar la movilización de las masas indígenas? La experiencia del movimiento de Túpac Ama$\mathrm{ru}$, no estaba demasiado lejos aún, y sabían que las hondas grietas de su sociedad se podrían acentuar y volcarse contra ellos mismos. Pero, al mismo tiempo estaban cansados, hartos y hastiadas de la supremacía política de los "europeos", acentuada desde las reformas borbónicas por un paulatino desplazamiento de los criollos en los altos cargos de la burocracia colonial 32. Frente a ello, ¿estarían los criollos dispuestos a llevar su lucha hasta las últimas consecuencias y formar una unidad con los indígenas? Los criollos consideraron, sin duda, la llegada de la Constitución, y su posterior juramentación como un éxito de ellos. También para los indios, como se ha visto, las promesas constitucionales fueron en gran parte vi- 


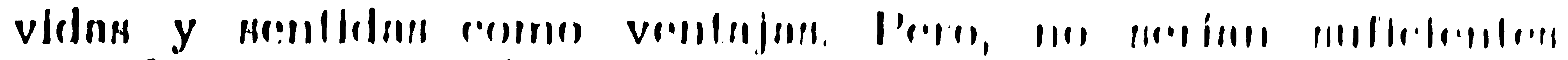

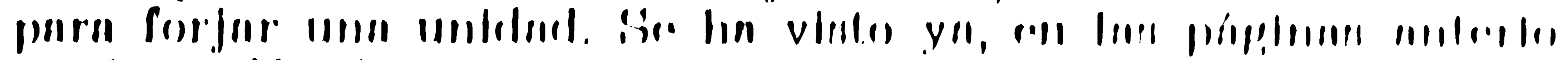

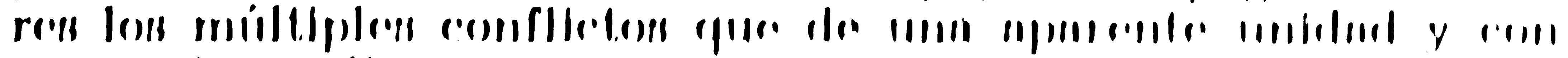

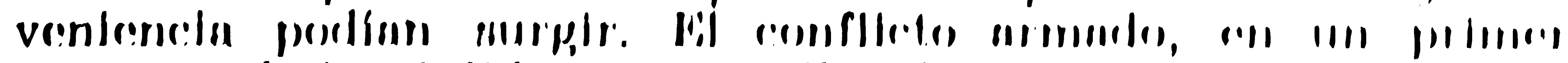

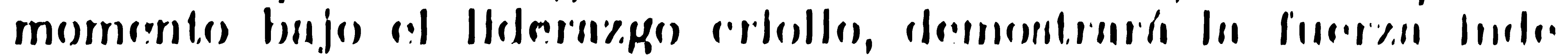

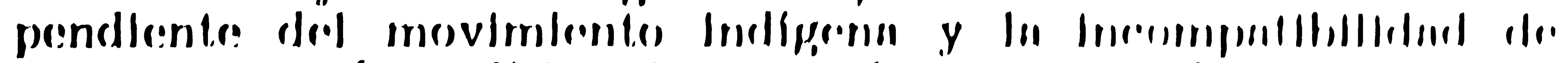

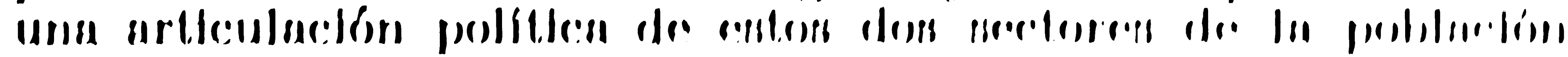
(es)lominl.

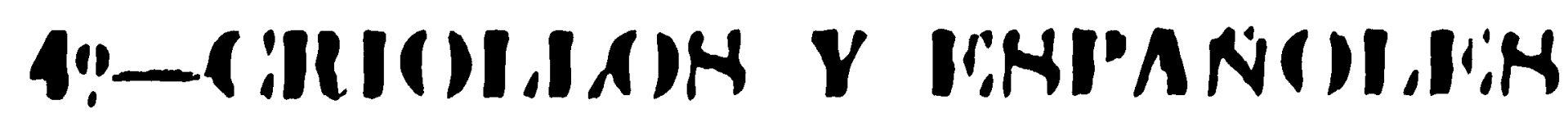

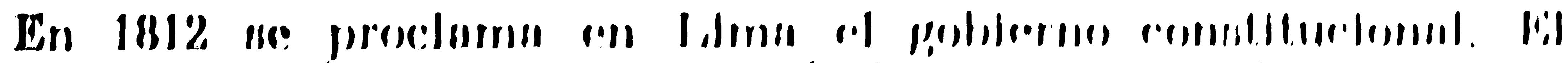

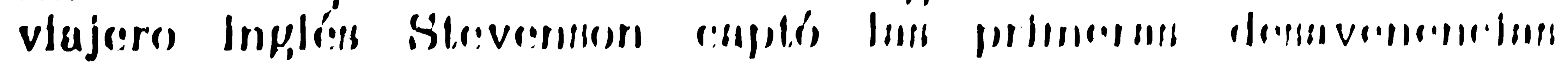

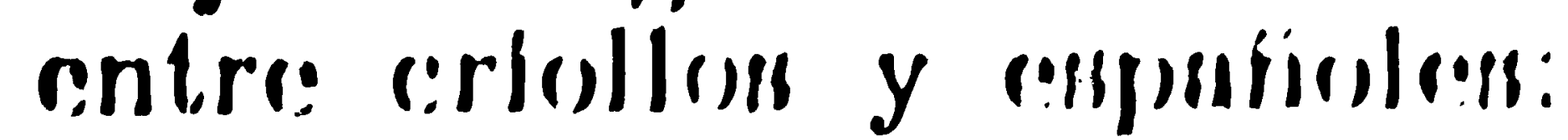

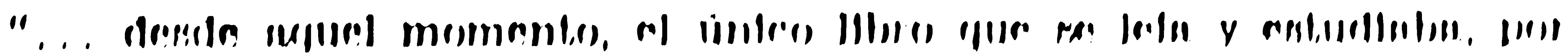

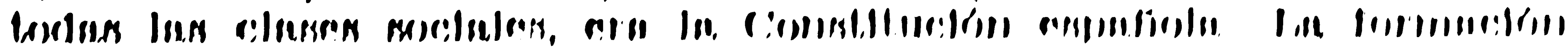

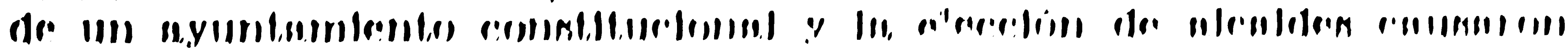

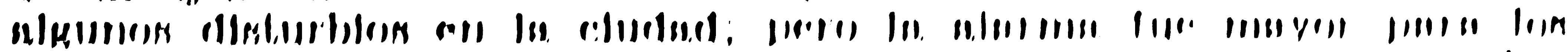

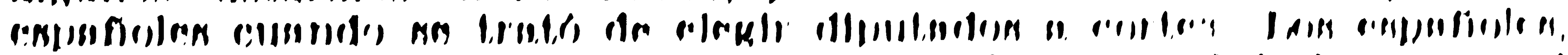

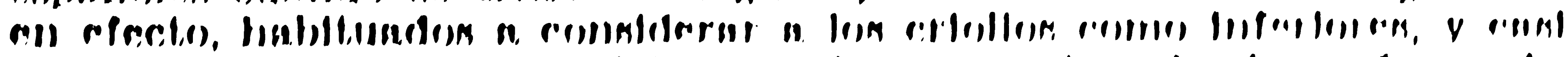

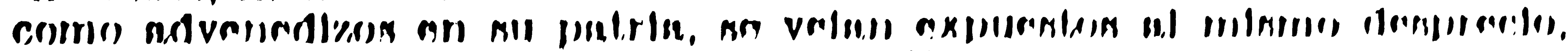

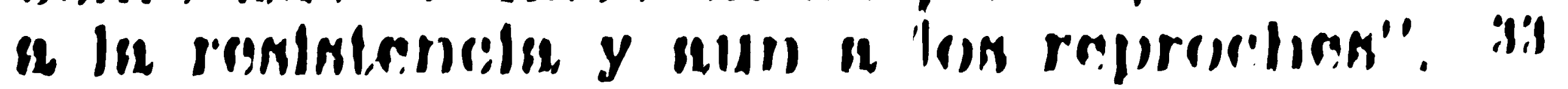

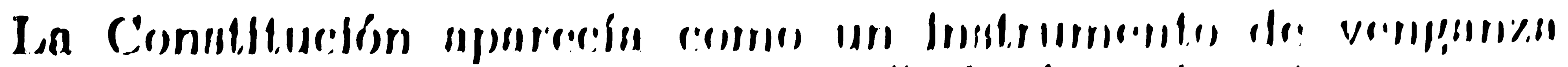

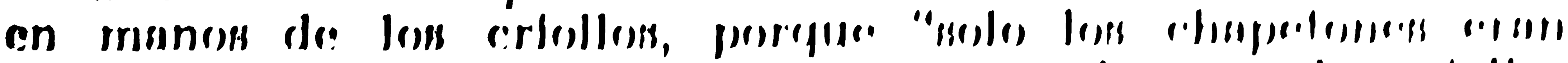

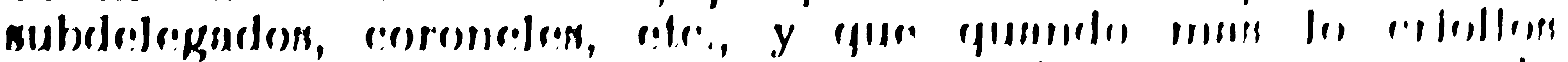

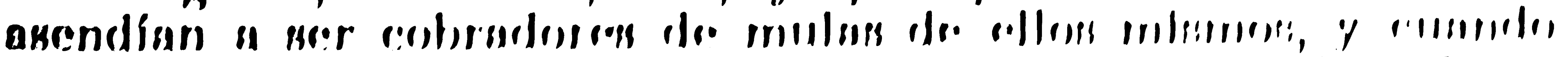

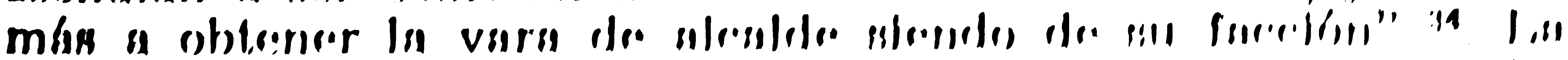

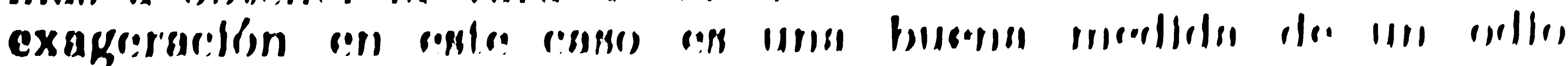

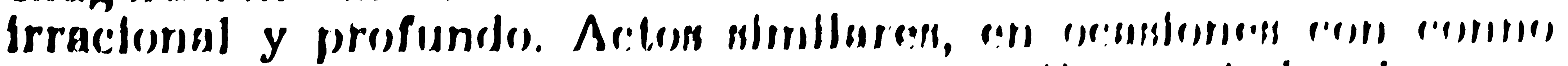

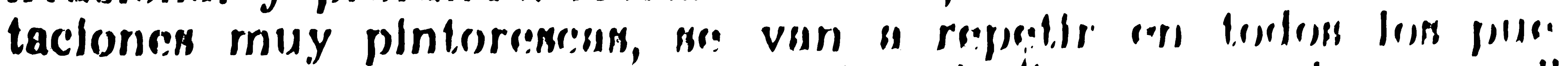

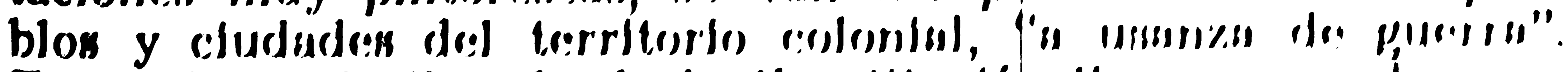

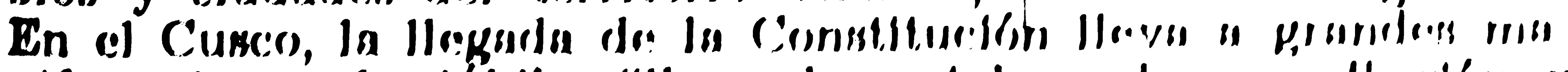

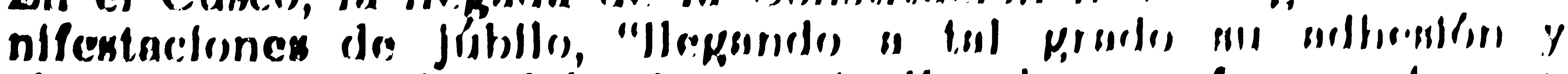

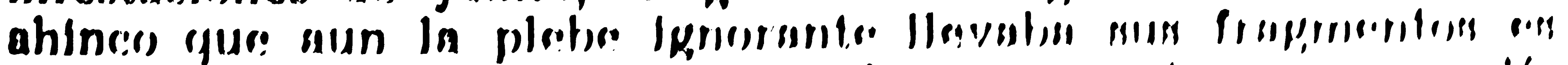

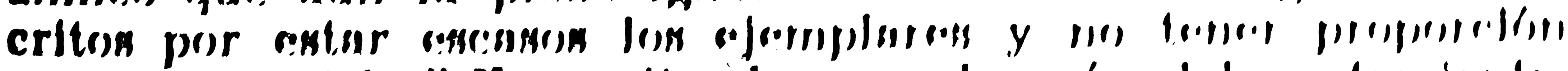

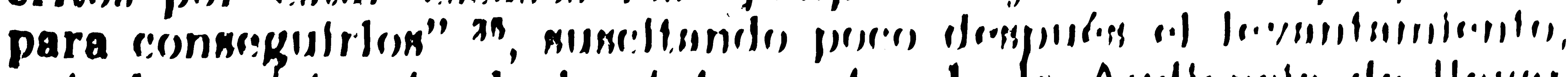

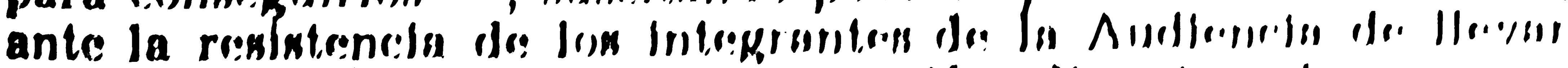

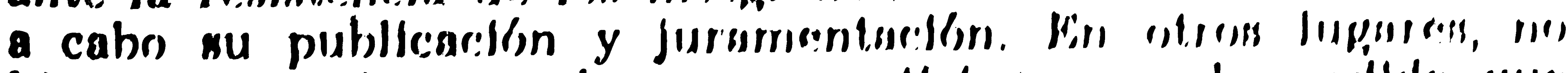

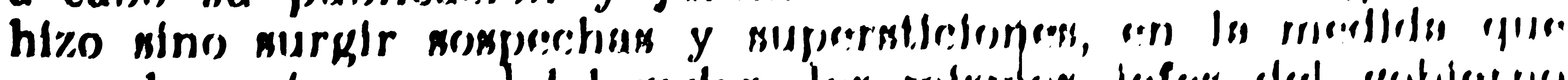

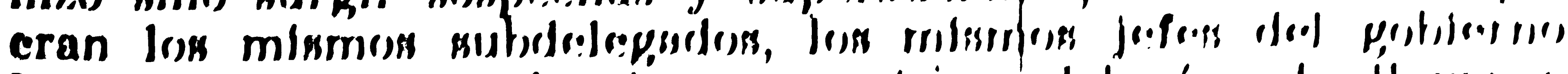

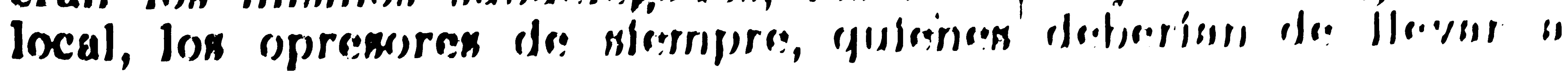


cabo su publicación. Un hecho significativo al respecto ocurrió en la localidad de Sihuas. Aquí se procedió a la juramentación en la iglesia, pero al terminar, "siete tixeras de la Iglesia que sostenían una bóveda postiza de yeso (se derrumbaron)... murieron diez indias y (entonces) el indio Antonio Alayo amotinatia a los de su clase, diciéndoles que aquella desgracia habia sllcedido por las leyes injustas que el subdelegado aciababa de publicar y así que se le prendiese y matase, pero no haciéudole (aso la multitud por la confusión... se continuó el sacrificio principiado ... Sin embargo, el referido indio Antonio Alayo (que) gritaba en altas voces, no jurasen unas leyes tan inucuas (...) logró que no se celebrase en aquella población por los indios la jura de la constitución... aunque sí lo hicieron los españoles y mestizos" 36. Eran "señales del cielo que confininaban la poca fe que se podía y debería de terles el indivationes promovidas por blancos y mestizos.

En lugares comm: ('aral'elí y Carnaná, los habitantes no perdielon mucho tiemus. Unilizaron la lectura de la Constitución para destituir directamente al subdelegado, llamando las cosas por su nombre, diciéndole "que era un ladrón, que la rapiña era su oficio" 37. Esto era relativamente fácil cuando al interior de la fracción criolla habían divisiones, mayormente entre constitucionalistas y conservadores, y donde los primeros eran más fuertes. Un acto similar, aunque de mucha mayor envergadura se dio en el Cusco, cuando los constitucionalistas al mando de los hermanos Angulo toman el Ayuntamiento apoyados en la Constitución que faculta, en efecto, la intervención popular contra los malos jueces $y$ administradores (art. 225). Demasiado tarde se percataron de que el virrey no sentía ninguna simpatía por estos actos, y menos por la Constitución. Y, era lógico, porque "los ciudadanos y vecinos bienavenidos con sus abusos y corruptelas, sentian su proscripción mediante lus planes provisionales, estados y proyectos que se habían criganicado (..) manifestaban la resistencia de despojarse de las injustas aunque antiguas facultades, pues acostumbrados a vivir en el despotismo, y a medir su poderío por su arbitrio y voluntad, miraban con odio y aversión las sagradas leyes fundamentales de nuestra constitución" 38 ¿Cómo, entonces, prescindir del apoyo indígena?

En Huánuco, desde fines de 1811, los criollos buscaron un acercamiento con los pueblos indígenas de los alrededores, por 
intermedio de cartas secretas que apuntaban a organizar una rebelión conjunta contra los españoles (que en Huánuco, además, parecen haber pertenecido a una sola familia). Los indios eran "hijos amados", a quienes se ofrecía favores e igualdad "en los tratos y comercios", pero a los que al mismo tiempo se advertía que no deberían atacar a los "señores sacerdotes, los templos y nuestros paisanos" 39. Tenían miedo y temores concretos. Los eventos que se sucederían a partir de febrero de 1812, momento en que estalla la rebelión por iniciativa de los indios panatahuas, y sin esperar el "disparo de meta" de los criollos, no los desengañarían. Luego de un jugoso saqueo de la ciudad de Huánuco apoyados por mestizos $\epsilon$ indios residentes en el recinto urbano, y sin darse el trabajo de diferenciar entre propiedades criollas y españolas ${ }^{40}$, los indios toman el ayuntamiento, y al serles comunicado un decreto de indulto de las Cortes, respondieron que querían una copia del decreto "para que tratándolo... resolviesen con acuerdo y madurez" en sus comunidades ${ }^{41}$ es decir, ni hermanos ni hijos, sino una clara demostración de que ellos iban a participar en las decisiones de ahora en adelante. Ante este primer ímpetu de las fuerzas indígenas, como era de esperarse, los criollos se dividen. Unos buscan rápidamente el respaldo de las fuerzas españolas en Jauja, otros aceptan el mando político por encargo de los indios ${ }^{42}$. Los indios intervienen directamente para trastocar las relaciones de poder en favor de los americanos. Pero, el desbande no se hace esperar. Se inicia, en parte por viejos conflictos de agua y tierra, las luchas entre los pueblos ${ }^{43}$, mientras por otro lado; las reivindicaciones son cada vez más de los indios, cada vez más profundas. Sistemáticamente se comienzan a fabricar hondas y huaracas "para la función de alzamiento" 44. Se procede a la toma de tierras.

En el obraje de San Rafael (al sureste de Huánuco) se levantó toda la comunidad del pueblo de Chacos, anexo de la doctrina de Huariaca, presidida por el alcalde de indios y otro lider, Josef Evangelista, a quien los indios llamaban Upayacu. El dueño responde que antes de tomar cualquier medida deberían de esperar la llegada del Intendente para pedir las chacras donde había un molino, "cedido" en años anteriores por el mismo común. Upayacu responde: "No, señor, lo que queremos es nuestras tierras prontamente porque ya es otro tiempo". Los indios de Tarma, propugnaban: "Somos dueños de todas estas 
tierras, y hemos de poser todas las casas y haciendas de Tarma". En Hamapsillo unas indias de Tarmatambo replicaron al hacendado, "que estaba engreído porque tenía concuñado chapetón... que mejor fuera se puciera a favor de los indios, porque aquellas tierras eran de los indios" 45. Estas actitudes realizaban en los hechos el iya basta! de los indios de Racayán y Piscamarca. Pero, al interior de la situación convulsionada de 1812 en Huánuco, estas acciones desataron odios más profundos. Rápidamente una situación planificada y reivindicativa se formuló a través de un frente étnico: acentuación de lo indígena y destrucción de todo lo ajeno. Había que exterminar a "los europeos, y a la buelta con los mestizos y blancos de esta ciudad, pues decían que havian comido el pan y que empezarian con los mistis" 46. Esta decisión llegó a tales extremos, que incluso indios "por ser amantes de los españoles" fueron asesinados 47. Mientras, las esperanzas criollas se iban desmoronando, crecía también la seguridad de que viejos y arraigados conflictos, firmemente enraizados en el inconsciente étnico, no podían ser borrados con un gesto liberal.

En el levantamiento del Cusco, dos años más tarde, las consecuencias no serían demasiado distintas. Aquí, la conciencia sobre la necesidad de incorporar a los indios al levantamiento se manifestó a través de dos hechos significativos. Por un lado, la incorporación de Mateo Pumacahua al levantamiento ${ }^{48}, y$ por otro lado por el hecho de que una persona como José Agustín Chacón y Becerra (abogado criollo del Cusco) optara por "borrar toda insignia y caracteres que pudieran recordar su real memoria", usando en cambio "las armas que setvian de ornato a (la) banda de Pumacahua". Pumacahua, sin embargo, "se las hizo quitar dándole un escudo de otros jeroglificos de los Ingas". También hacía "alarde de ser noble descendiente de los antiguos Incas, al paso que Pumacahua en su declaración expresa ser ésta una falsa suposición que sólo envolvía la mira de conciliarse la opinión y respeto de los indios hacia su persona" 49. Esta era la actitud cuando se necesitaba de los indios Otra era, sin embargo, cuando los indios se presentaban como competidores por los puestos de poder. Tal vez nadie expresó esto más claro que el mismo Pumacahua, como Presidente interino de la Audiencia del Cusco, en los momentos en que el coronel Martín Concha, comandante de armas de la plaza lan- 
zaba contra Vidaurre, oidor de la audiencia el insólito insulto de ser "mulato libertino" 50, al decir que:

"Son muchos los que aborrecen mi graduación, los que desconocen mis servicios, los que odian $\mathrm{mi}$ mando por $\mathrm{ml}$ inaturaleza Indica (...) Ya intentan desconocer con el escudo de la constitución, que sólo quieren cumplir en lo que les conviene, y en lo que no se alejan de ella ..." $\mathrm{j}_{\mathrm{i}}$

Los resultados de estas desavenencias, y los profundos conflictos que ellas reflejaban fueron descritos con mucha lucide.: por el Mariscal de Campo Juan Ramírez:

"Por general que fuese la tendencia e inclinación de los pueblos hacia su sistema, es preciso confesar que el exceso de las inauditas acciones que estos hombres inmorales cometieron desde sus primeros pasos, había arredrado a no pocos individuos, y convencido a los más que la revolución y la guerra se dirigía contra todos los que tienen que perder (...esto hará) slempre estériles e Infructuosas en el Perú todos los esfuerzos y planes de los revoltasos incompatibles con su situación e irrealizables entre la diversidad de castas que le habiten y entre los opuestos intereses que animan a cada una de ellas". 52

Finalmente, hay más evidencias, que no porque todavía no pueden explicarse integralmente, deban callarse, y que a pesar de ser ejemplos y constataciones aisladas o tal vez mal transmitidas del universo indígena, dejan de tener significado en relación a lo descrito en las páginas anteriores. Todo lo contrario. Pueden ser considerados una posible forma de explicar mejor los mecanismos de las agrupaciones indígenas durante los levantamientos, tal vez sus desavenencias internas, y todo lo que encierra el término "inconsciente étnico". ${ }^{53}$

¿Por qué esa meticulosidad puritana de Pumacahua, al aclarar que a Becerra no le correspondían las insignias que usaba, falseándolas obviamente en función a cometidos ajenos a los cuales estaban destinadas? ¿De dónde se deriva la certeza criolla de que los indios responderían al llamado de estos ornatos? Preguntas similares surgen en el caso de Huánuco. Durante los levantamientos descritos no cesaron las incursiones de los ejércitos patriotas en el Alto Perú. Sus lícieres, de los cuales uno era Castelli, mantenían comunicación con los diferentes focos patriotas en el Virreynato peruano. Pero, mientras para los criollos patriotas Castelli fue lo que realmente era, un líder patriota, para los indios, Castelli fue el hijo o el pariente del Inca. Mientras los criollos esperaban poder 
coordinar sus acciones para liberarse de la dominación española, los indios divulgaron la imagen de este personaje como redentor de toda opresión, a quien deberían de recibir "baylando a la moda de los Chimos antiguos" 54. Era, está casi de más decirlo, un Rey Inca que venía "a cortar el pescuezo a todos los hlancos". ¿De dónde, entonces, y cómo se dio la prosibilidad de que restuggiera una asociación de este tipo? Aun suponiendo que fuela un ardid usado por los criollos para incorporar a las huestes indigenas, queda la pregunta de por qué pudo ser tan efectiva, o por qué esta imagen surge en Huánuco y no en Lima o en el Cusco.

A pesar de que la respuesta a estas interrogantes requiere otro tipo de análisis, que iría demasiado lejos para los intentus presentes, creo que hay una conclusión válida en relación a lo expuesto. El ser indio en una sociedad multiétnica era mucho inás que simples rasgos raciales, o simples signos de dominación, era también una vivencia cultural, fuerte y presente, a pesar de tres siglos de vida colonial. Era una fuerza que impulsaba a las masas indigenas, a la vez que representa en la esfera ideológica la prueba de la diversidad con que un uismo hecho podia ser entendido e interpretado. La apreciación tan distinla de lo que se suponía debería de ser un solo destino pulítico era la base y al mismo tiempo la expresión totalizante de la imposibilidad de conjugar credos, intereses y proyectos.

\section{CONCLUSIONES}

De lo enunciado y descrito se desprenden algunos resultados importantes.

Ias discusiones preliminares en torno a la nueva constitución, así como su implementación y juramentación en las colonias produjo reacciones variadas y fuertes. El intento constitucional hizo surgir los antagonismos inherentes a una sociedad estratificada $\Varangle$ multiétnica como la peruana. Estas contradicciones se dieron en parte porque fracciones importantes de la sociedad indigena habian adquirido hasta este período posiciones sociales y económicas que no eran más compatibles con discriminaciones de carácter étnico. El indio estaba decidido a participar en su destino político, y no a ser excluido 
por los grupos de poder. La Constitución fue un camino que se abrió para estas reivindicaciones. No sólo se acortó la distancia entre la metrópoli y sus colonias, sino también entre los diferentes espacios coloniales. La Constitución fue leída y juramentada en los lugares más apartados y pudo, por tanto hacer surgir respuestas, de acuerdo a la situación específica y concreta de cada uno de estos lugares. Estas respuestas variaron desde la defensa por las armas, hasta el afloramiento de supersticiones pueblerinas, demostrando en su conjunto la diversidad $\mathrm{y}$ el entrecruzamiento múltiple, variado y pintoresco de los conflictos de la sociedad colonial en su conjunto. Demostró la debilidad de los líderes tradicionales de las comunidades, de los pueblos; la pérdida de su ascendiente ideológico, la pérdida de su capacidad económica, y demostró a las comunidades su capacidad de resistencia con fuerzas congregadas. Las clases dominantes derivaron, una vez más, de esta experiencia la angustia y el temor que la participación indígena significaba. La corona española sustentó y justificó este temor, forma certera de asegurar, aunque por poco tiempo, su dominio sobre las colonias. Las respuestas indígenas ahí donde contaron con el apoyo - al menos temporal- de los criollos, pudieron surgir con gran fuerza y expandirse una vez iniciadas más allá del control de los criollos, determinando que éstos se desprendieran de la euforia revolucionaria inicial y buscaran refugio en los ejércitos realistas. Con la separación de los criollos, los movimientos perdieron a sus más probables líderes, así como el sustento económico que a través de su presencia podían obtener. No faltaron tampoco el resurgimiento, durante estos conflictos armados y estas demostraciones de protesta, de conflictos al interior de la misma sociedad indígena. Se evidenciaron en las batallas entre los pueblos en el levantamiento de Huánuco, incentivados por luchas antiguas por agua y tierras, hábilmente sustentadas y mantenidas por los hacendados circundantes, y en los conflictos por el poder al interior de la misma comunidad, donde unos plegaron sus intereses a los de los grupos dominantes de poder, sometiéndose a ellos y haciéndoles concesiones de tierras, aguas y pastos comunales, y otros que se levantaban contra estas usurpaciones disfrazadas y clamaban ante los fueros y con armas en las manos, ante los tribunales, en las puertas de las casa-haciendas, y de los ayuntamientos constitucionales. 
Estas contradicciones en su conjunto tuvieron oportunidad de mostrarse, y demostrar la imposibilídad de una reestructuración de la sociedad colonial bajo los auspicios y postulados de sus representantes en Cádiz. Eran culturas, razas e intereses en abierto conflicto, sin una clara supremacía y por tanto sin líneas directrices para toda la sociedad, capaces de convertirse en 1815 en una voz unificada por la reforma constitucional, mucho menos por la independencia. 


\section{NOTAS}

1 Rubên Vargas Ugarte, Historia General del Perú, vols. 5 y 6 . Llma 1966.

Jorge Cornejo Bouroncle, Pumaca. hua: La Revolución del Cuzco de 1814. Cusco, 1956

José Varallanos, Historia de IIuá. nuco, Buenos Aires, 1959.

2 Guillermo Durand Flórez, (comp.). en Colección Documental de la In. dependencia del Perú, (en adelante CDIP) T. 4, vol. 1, p. XIII, LIma, 1974.

3 Los problemas que se interpusieron a la salida de los diputados están descritos ampliamente en al. gunos casos. Ver p. ejemplo CDIP, t. 4, vol. 2, pp. 28-32 (D. José Mariano de Ugarte para el Cusco): t. 4, vol. 2, pp. 475-499 (D. J. Ustárlz para Arequipa); t. 4, vol. 2 , pp. 502-521 (Huamanga); t.4. vol. 2 , p. 522; t. 4, vol, 2, pp. 420.24 (el obispo Pemigio para La Paz).

4 James F. King, "The Colored Castes and American Representation in The Cortes of Cádiz", in HAHR, vol. 3, Agosto/Set., 1953.

5 CDIP, t. 4, vol. 1, p. 326. Inter. vención del delegado peruano Morales Duárez en la sesión del 21 de agosto de 1811 sobre el "Proyecto para que los indios no sean considerados menores".

6 Jbid., p. 243, intervención del delegado peruano Sr. Feliú en la sesión del 13 de marzo de 1811 en la "Discusión sobre la propuesta para que no se restablezcan los repartimientos".

7 James F. King, op. cit.; p. 56.

8 Estuardo Núnez, (comp.), in. CDIP, Relaciones de Viajeros, t. 27. vol. 3." "Memorlas sobre las campanias de San Martín y Cochrane en el Perú", de William Bennet Stevenson, pp. 116 y 161 .

9 CDIP, T. 4, vol. 2, pp. 162.163, in. forme sobre el estado de la agricultura, la industria y los tejidos para el partido de Carabaya. para ser entregado al representante a Cortes. Carabaya, 3 de noviembre de 1812 .

10 Ibld., vol. 1, pp. 527 y sgts., y vol. 2, p. 160 y sgts.

11 Ibid. vol. 1, pp. 525/6, carta del Cabildo de Lambayeque. Lam. bayeque, 10 de octubre de 1811 .

12 Llévano Aguirre. Los grandes conflictos sociales y económicos de nuestra historla. 4 vols.. Bogotá. 1963, yol. 3, p. 196, citado por Nicolás Sánchez Albornoz en Indios $\mathrm{y}$ tributarios en el Alto Perú, Lima. $1978, \mathrm{p} .193$.

13 Archivo General de la Nación (en adelante AGN). Derecho Indígena. Actos promovidos por los indlos del pueblo de Carama, en el partido de Yauyos. contra los abul. sos en el cobro de las alcabalas y otros impuestos. C. 758, 1816 .

14 Biblioteca Nacional (en adelante BN), oficlo del Virrey al Obispo de Arequipa, Isima 1814 (?) D 11710 .

15 Pablo Macera (comp.) "Razón circunstanciada que $D$. Martín de Garmendia, diputado del comercio del Cuzco produce al Consulado de Isima con relación de los ramos de industria de aquella provincia", en Revista del Archivo Nacional, p. 247, Lima, 1964.

16 Manuel Jesús Aparicio Vega (comp.), en CDIP La revoluclón 
de 1814, t. 3, vol. 8, p. 478, Carta de José Antonio de Areche a D. Mateo Pumacahua, Cuzco, 18 de ju. lio de 1781 .

17 Ibid., p. 544, carta de Mateo Pumacahua al Virrey. Cuzco, 11 de Noviembre de 1812 .

18 AGN. Derecho Indigena. Autos yue Eugenio Quispe y Pedro Itjylari. indios tributallas del puc. blo de 'liquillinia, th la Intendencia de russo, ploullovitioll pul sl, y en nombre de su común contra Dña. Margarita Tinajero, mujer que fue del cacique $\mathrm{D}$. Andrés $\mathbf{C a}$ lisaya, quien a título de viuda del referido cacique usufructuaba las tierras del Cacicazgo, se intitulaba cacica, y monopolizaba la sal y extorslonaba a los pobres indios, negándose a pagarles sus joinales cuando les mandaba hacer algún trabajo en sus tierras y heredades. C. 574, 1802 .

19 Ibid., Autos promovidos por $\mathrm{D}$. José Palacios, vecino del pueblo de Gorgor, en el partido de Cajatan. bo contra los indius de la comul. nifad de Racayan, sulsie el incumplimlento de un contrato de dires. damiento en los pastiss denomina. dos Huancacocha, de propiedad de la referida comunidad. C. 754, 1815.

20 Para este proceso, N. Sánchez Albornoz, in op. cit. presenta un análisis minucioso y detallado.

21 BN, Expediente reservado seguido por el vicario del partido grande de Lama, Dr. D. Andrés Bor. nas, sobre los pascjulines puestos en el partido de Azángaro, a consecuencia de las prevenciones de este gobierno intendencia de Puno. Puno, 30 de noviembre 1818, D 5905.

22 AGN. Derecho Indígena. Au. tos que siguló D. Juana de Boza, vecina de la ciudad de Lima, contra los indios mitayos de la doctrina de Magdalena de Cajatambo y sus anexos sobre la indemnización de los daños y perjuicios que le ha. bian sobrevenido a su hacienda de San Antonio de Colpa, por el abandono que hicieron los dichos indios del servicio de la mita y de los galiados que apasentaban. C 652 . 1807

23 AliN. Derecho Indigena. Que. rellia que interpuso el Protector de los Natura'es del Partido de Ica, Juan Gregorio Saavedra contra el juez Subdelegado de dicho partido acusándole de haber impelido en fuerza de su autoridad a los Alcaldes de indios, a que le diesen jornaleros para las labores de la hacienda de Caucato y que los dichos alca!des se habian visto precisados a reclutar gente forzadas y a darle hasta 40 hombres. C. 577, 1802 .

24 AGN. Derecho Indigena. Autos que los indios de la comunidad del pueblo de Pampas en el partido de Huaylas, promovieron contia el subdelegado de dicho partido, sobre que se les satisfaciese el costo de 150 caryas de cal que condujeron para la obra de la fuente pública que se está construyendo en el pueblo de Huaráz, y que en adelante no se les pencionase con trabajos gratuitos $y$ onerosos C. 572,1802 .

25 AGN. Real Audiencia. Causas Criminales. Causa seguida contra Tadeo Efio por "inquietador de la pública tranquilidad, so pretexto de defensor de los naturales". L. 135 , C. 1642,1817 .

26 AGN Derecho Indigena. Autos promovidos contra D. Ventura Cal. derón, indio originario del partido de Cajatambo para que se abstenga 
de promover continuos juicios en nombre de los indios de la docirina de Nuestra Señora de las Nieves, Mullay, Pachangara, Curay y Rapaz, con cuyos procedimientos alteraba la tranquilidad de aquellos in. dios. C. 729, 1810.

\section{AGN Id. cita 25.}

\section{AGN Id. cita 18.}

29 BN. Copia del acta expedida en Junta General Extraodinaria de Tribunales del 14 de noviembre de 1812. D 11680.

30 BN. Expediente formado por el señor Gobernador de Guayaquil contra varios indios del pueblo de Jipijapa, Jipijapa, setiembre de 1817.

31 En torno al establecimiento de la nueva contribución, $y$ apoyado en un extracto de las Memorias de Abascal, Sánchez Albornoz op. cit., dice lo sigulente:

"el virrey establectó una contribución vo'untaria de los indios. La me. dida revestía carácter temporal. Las Cortes habían previsto la sustitución del tributo por otro impuesto que deberian de abonar todas las clases del estado y no solamente los aborigenes. La implan. tación de esta única y directa contribución personal resultaba' empe. ro "más onerosa para aquellos (los indios) y de laborloso y difícil es. tablecimiento en el reino" (Abascal, Memoria, I, 288-292). Agrégue. se que podía suscitar la enemistad de las clases antes exentas. El nuevo impuesto quedó, pues, re'egado, y se volvió al antiguo sistema, so capa de tasa voluntaria.

32 Burkholder. "From Creole to Peninsular: The Tranformation of the Audiencia of Lima" en HAHR, vol. 52, No 3, Agosto, 1972, pp. 395. 415 .
33 CDIP, t. 27, vol. 3, op. cit. p. 238.

34 Ella Dunbar Temple (comp.), en CDIP, La Revolución de Huánuco, Panatahuas y Huamalíes de 1812 , t. 3, vol. 2, p. 392, Confesión del Presbitero D. Tomás Nal. varte.

35 CDIP, t. 3, vol 5.u., p. 188. Nota del Ayuntamiento del Cuzco al Virrey de Lima. Cuzco, 26 de febrero de 1813.

36 CDIP, t. 4, vol. 2, p. 277. Acta del juramento de la Constitución en el pueblo de Sihuas el 19 de fe. brero de 1813.

37 AGN. Superior Gobierno. Expediente que contiene la descrip. ción de los atentados cometidos en Caravelí y Camaná a raf́z de la eectura de la Constitución. L. 34, C 1154 .

38 CDIP, t. 3, vol. 7, 128, Acuerdo del Cabildo del Cuzco del 25 de se. tlembre de 1813.

39 CDIP, t. 3, vo!. 4, pp. 195_227. Relación verídica y auténtica de la Revolución que estalló en la ciudad de León de Huánuco el sábado 22 de Febrero de 1812, escrito por el Dr. Pedro Angel Yadó (Síc), Cura español de la Doctrina de Huanaca diriglda al Ilustrísimo se. ñor Doctor Fray Bartolomé de las Heras, Arzobispo de Lima. 19 de Marzo a 19 de Setiembre de 1812 . También citado por José Varalla. nos in op. cit., pp. 450-469.

40 CDIP, t, 3, vol. 2, p. 169. Carta de Fray Marcos Durán Martel a los señores Alcaldes. Huánuco, 10 de Marzo de 1812.

41 CDIP, t. 3, vol. 1, pp. 92-97. Relación de varios testigos sobre el saqueo en Huánuco. Febrero, 1812. 
42 CDIP. t. 3, vol. 1, pp. 264-74, varios informes sobre la invasión indígena a Huánuco suscritos por los integrantes del Ayuntamiento. Febrero/Marzo 1812. Los Indios in. terceptan las cartas del Pdte. del Ayuntamiento Domingo Berrospi, en las que busca justlficar la actuación de los criollos en Huánuco, pidiendo al mismo tiempo ayuda. Los indios lo destituyen y nombran a José Crespo y Castillo en su lugar, CDIP, t. 3, vol. 1, pp. 110-112 carta de justificación de Domingo Berrospi, Huánuco 27 de Febrero de 1812 (?). Pasco, 4 de Marzo de 1812. t. 3, vol. 1, pp. 251-2. Relación que hacen los integrantes del Ayuntamiento en torno a los sucesos menclonados. Huánuco, 20 de marzo de 1812 .

43 CDIP, t. 3, vol. 3, p. 23. Recurso presentado por José Lucas y José Briceño, vecinos del pueblo de Chupán y presos al Sr. Justicia Mayor. Mayo de 1812 .

44 CDIP, t. 3, vol. 4, p. 544. Confesión del indio Nasario Flores. Huánuco, abril de 1812.

45 CDIP, t. 3, vol. 1, pp. 130, 131 y 143. Declaraciones de Jua na Cochachi, Orieta, ladina en la lengua castellana de $\mathrm{D}$. Basillo $\mathrm{Ba}$ llina, dueño de la haclenda de Acobamba (doctrina de Pallanchacra) y de Tiburcio Gómez, soldado $\mathrm{ml}$ liclano, respectivamente.

46 CDIP, t. 3, vol. 2, p. 159. Confesión de Agustín Acosta, labrador. mestizo; y t. 3, vol. 4, p. 440. Confesión de Enrique Chagua, soldado de regimiento, natural de $\mathbf{P a}$ chas.

47 CDIP, t. 3, vol. 3, p. 45. De. claración del testigo Mateo Goyo, natural y vecino del pueblo de $\mathrm{Chu}$ pán.
48 Los motivos de la incorporación de Pumacahua al bando cons. titucionalista, luego de haber sido flgura principal en el sofocamiento del levantamiento de 1780 , es una de las grandes interrogantes de la historlografía. Se han aducido relaciones familiares, codicia por el mando, e incluso ignorancia como argumentos. Creo que la exp'icación es la propia inconsistencla política de la época. La constitución venía firmada por el Rey y el mismo Abascal, luego también La Serna, Canterac y Valdés pertenecieron al partido constitucional. Nadie sabla qué consecuencias tendria este levantamiento. (Al respecto véase Benjamín Vicuña Mackenna, La independencia del Pe. rú, 5. ed. Buenos Alres. 1971, p. $111, y$ las obras enumeradas en clta (1)).

49 CDIP t. 3, vol. 7, p. 295. Copla del dictamen fiscal contra José Agustín Chacón y Becerra.

50 AGN. Real Audiencia. Causas Criminales. Autos Criminales seguldos ante la Audiencia del Cuzco por el Oídor de la misma, contra el Coronel Martín Concha, comandante de Armas de esa Plaza por el delito de haberse puesto al. tivo profiriendo palabras injuriosas en pandilla, tanto de obra como de palabra en agravio del señor Oidor Manuel Vidaurre, cuando salía de la sala del Tribunal la tarde del día 22 de agosto de 1811. L. 122, C 1481, 1811 .

51 CDIP. t. 3 vol. s.n., p. 205. Oficio de Pumacachua al virrey, 26 de abril de 1813. A este oficio habia precedido una carta del abogado constitucionalista Ramírez Arellano a la Sala Consistorial (del 9 de abril de 1813) en la que se acusaba a Pumacahua de ser un 
usurpador del puesto que ocupaba. BN, D. 8898 .

52 CDIP, t. 3, vol. s.n., p. 250 Diario de la expedición del Marlscal de Campo D. Juan Ramírez sobre las provincias interiores de $\mathrm{La}$ Paz, Puno, Arequipa y Cuzco.

53 Entendido, este término, no en la forma jungiana, sino así como fuera utilizada por George Deve reux en su libro "De la ansiedad al método en las ciencias del com. portamiento". Madrid, 1977, es decir, aquella que a todos los miem. bros de un grupo dado se les enseña sistemáticamente a reprimir.

54 CDIP, t. 3, vol. 1, pp. 133 y 143. Declaraciones de Marina Inés Ramos ,india de 80 años $y$ de THburcio Gómez, soldado miliciano, respectivamente. 